\title{
Triptans and third nerve paresis: a case series of three patients
}

ES Novitskaya ${ }^{1}$, CA Cates ${ }^{1}$, OM Bowes ${ }^{1}$ and AJ Vivian ${ }^{1,2}$

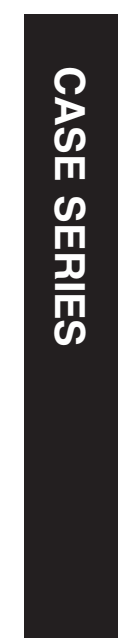

\begin{abstract}
Purpose The aim of this report is to increase awareness of a possible association between cranial nerve paresis and the use of sumatriptan in migraine sufferers, particularly in patients who have additional vascular risk factors. Patients and methods We describe a series of three cases where third nerve paresis developed in patients who were treated with the oral form of sumatriptan. All of the patients had a clear history of repetitive migraine headache and none of them had previous third nerve paresis. Conclusion Among a variety of medications for the treatment of migraine, there are some drugs with vasoconstrictive effects, particularly triptans. These drugs may be a contributing factor for microvascular damage of the cranial nerves and other organs. Eye (2017) 31, 503-505; doi:10.1038/eye.2016.256; published online 18 November 2016
\end{abstract}

\section{Introduction}

Microvascular third nerve damage is typically diagnosed in patients with vascular risk factors, when other causes of acute ocular motor mononeuropathies have been excluded. ${ }^{1-3}$ There are also conditions more rarely associated with isolated cranial nerve paresis, particularly migraine, where the exact mechanism of the nerve damage is not well understood. ${ }^{4,5}$

The triptans are among a number of migraine treatments that have a vasoconstrictive mechanism of action. ${ }^{6}$ There are sparse case reports in the literature describing different ischaemic side effects of this drug group. ${ }^{5,7-13}$

We report three cases where third nerve paresis developed in patients who were treated with oral sumatriptan for recurrent nonophthalmoplegic migraine.

\section{Case 1}

A 19-year-old man presented 3 days after an episode of severe headache and nausea, which resolved after a single oral dose of sumatriptan
$50 \mathrm{mg}$, following which he developed right pupil sparing third nerve paresis. He had never used sumatriptan before. There was no relevant past ocular history. He had suffered from recurrent classical migraines for 3 years without visual symptoms or double vision and was an occasional smoker. His symptoms and the third nerve paresis completely resolved 3 months later.

\section{Case 2}

A 63-year-old woman presented with a 10-day history of generalised headache followed by horizontal diplopia and partial left ptosis. She had experienced a similar episode 2 months previously and on both occasions took oral sumatriptan $50 \mathrm{mg}$ at the peak of the headache before developing double vision and ptosis. Examination showed a left pupil sparing partial third nerve paresis. She had no other past ocular or medical history apart from recurrent migraine for 15 years with no ocular symptoms. She had taken sumatriptan $50 \mathrm{mg}$ approximately three times a year for the past 3 years. The patient's symptoms and third nerve paresis completely resolved at 4-month follow-up.

In both cases, neurological assessment and further investigation, including MRI, MRA, inflammatory markers, anti-AChR antibodies, and single fibre EMG, revealed no other cause of acute third nerve paresis.

\section{Case 3}

A 74-year-old female presented with a 7-day history of right-sided headache with progressive horizontal and vertical diplopia and right ptosis. Examination showed a right pupil sparing partial third nerve paresis. Past medical history included successful surgery for a right frontal lobe meningioma 18 months previously, well controlled non-insulin-dependent diabetes for 3 years, and migraine since very young age. The pattern of migraine headache did not change after neurosurgery and the patient described her
${ }^{1}$ Department of Ophthalmology, West Suffolk Hospital, Bury St Edmunds, UK

${ }^{2}$ Department of Ophthalmology, Addenbrooke's Hospital, Cambridge, UK

\section{Correspondence:}

ES Novitskaya, Department of Ophthalmology, West Suffolk Hospital, Hardwick Lane, Bury St Edmunds, Suffolk IP332QZ, UK Tel: +44 (0)79 6904 8873; Fax: +44 (0)140803 63693. E-mail: elena.novitskaya@ gmail.com

Received: 26 August 2016 Accepted in revised form: 30 September 2016 Published online: 18 November 2016 
current headache as her 'usual migraine'. Apart from her regular medications (metformin, atorvastatin, fluoxetine, esomeprazole, and ondasteron), she had started to take oral sumatriptan $50 \mathrm{mg}$ on alternate days 5 days before the onset of diplopia. Neurological assessment, blood pressure, blood glucose, $\mathrm{HbA} 1 \mathrm{C}$, and inflammatory markers were normal. Urgent neuroimaging, including CT, MRI, and MRA, showed no new abnormalities compared with previous imaging. One week after presentation, the patient's symptoms progressed. She felt light-headed with increasing headache and the right pupil sparing third nerve paresis progressed so that she developed complete ptosis. On admission to hospital, she admitted that for the past week she had taken sumatriptan $50 \mathrm{mg}$ almost every day. The medication was discontinued and 1 month later, the patient's headache had completely resolved. The third nerve paresis completely resolved at 4-month follow-up.

\section{Discussion}

Pathophysiology of migraine is not well understood. ${ }^{5}$ However, some of the clinical manifestations of migraine, particularly aura, are believed to result from vasospasm followed by vasodilatation of cranial vessels. ${ }^{5}$

Triptans are widely used as rescue treatment for migraine due to their vasonstrictive effect and are considered to be a relatively safe treatment. ${ }^{11,14,15} \mathrm{We}$ believe that the vasoconstrictive effect of sumatriptan may result in ischaemic side effects, which may be underreported.

There are only two case reports describing an association between sumatriptan and cranial nerve palsies. ${ }^{11}$ Rothner et al ${ }^{11}$ reported a case of facial nerve palsy in a teenager using sumatriptan nasal spray. Hossein et al ${ }^{13}$ described a recurrent paresis of the superior division of the oculomotor nerve occurring after subcutaneous administration of the drug.

Although case 3 had additional vasculopathic risk factors and a previous history of a microvascular event, the other two cases were otherwise healthy and we feel their cranial nerve damage was most likely drug related. In case 3, the frequent use of the medication could have caused an additional vasoconstrictive impact, which resulted in third nerve paresis.

We believe that these cases demonstrate a possible association of microvascular third nerve paresis with sumatriptan intake.

This should be considered when this medication is prescribed to migraine sufferers, particularly when other vascular risk factors are present.

\section{Summary}

What was known before

- Triptans have a vasonstrictive effect but are considered to be a relatively safe treatment.

- There are sparse case reports in the literature describing different ischaemic side effects of this drug group, including gastrointestinal and spinal necrosis, placental infarction, facial nerve paresis, ischaemic colitis, myocardial infarction, and transient paresis of the superior division of the oculomotor nerve after subcutaneous injection of sumatriptan.

What this study adds

- Our case series describes possible association of microvascular third nerve paresis with oral intake of sumatriptan in three individuals.

- This must be considered when this medication is prescribed to migraine sufferers, particularly when other vascular risk factors are present.

\section{Conflict of interest}

The authors declare no conflict of interest.

\section{References}

1 Tamhankar MA, Biousse V, Ying GS, Prasad S, Subramanian PS, Lee MS et al. Isolated third, fourth, and sixth cranial nerve palsies from presumed microvascular versus other causes: a prospective study. Ophthalmology 2013; 120(11): 2264-2269.

2 Tamhankar MA, Volpe NJ. Management of acute cranial nerve 3, 4 and 6 palsies: role of neuroimaging. Curr Opin Ophthalmol 2015; 26(6): 464-468.

3 Sadagopan KA, Wasserman BN. Managing the patient with oculomotor nerve palsy. Curr Opin Ophthalmol 2013; 24(5): 438-447.

4 Bek S, Genc G, Demirkaya S, Eroglu E, Odabasi Z. Ophthalmoplegic migraine. Neurologist 2009; 15(3): 147-149.

5 Asghar MS, Hansen AE, Amin FM, van der Geest RJ, Koning $\mathrm{P}$, Larsson $\mathrm{HB}$ et al. Evidence for a vascular factor in migraine. Ann Neurol 2011; 69(4): 635-645.

6 Chan KY, Labruijere S, Ramirez Rosas MB, de Vries R, Garrelds IM, Danser AH et al. Cranioselectivity of sumatriptan revisited: pronounced contractions to sumatriptan in small human isolated coronary artery. CNS Drugs 2014; 28(3): 273-278.

7 Triptans: beware of vasoconstrictive effects. Prescrire Int 2014; 23(153): 240.

8 Hodge JA, Hodge KD. Ischemic colitis related to sumatriptan overuse. J Am Board Fam Med 2010; 23(1): 124-127.

9 Nguyen TQ, Lewis JH. Sumatriptan-associated ischemic colitis: case report and review of the literature and FAERS. Drug Saf 2014; 37(2): 109-121.

10 Repaka A, Wenger J, Sitaraman SV. A case of sumatriptaninduced intestinal ischemia. J Gastroenterol 2006; 41(2): 177-178.

11 Rothner AD, Winner P, Nett R, Asgharnejad M, Laurenza A, Austin R et al. One-year tolerability and efficacy of sumatriptan nasal spray in adolescents with migraine: 
results of a multicenter, open-label study. Clin Ther 2000; 22(12): 1533-1546.

12 Sharma SG, Post JB, Herlitz LC, Markowitz G. Renal cortical infarction following treatment with sumatriptan in a kidney allograft recipient. Am J Kidney Dis 2013; 61(2): 326-329.

13 Hossein GC, Chane M, Sadun AA. Ocular motility problems associated with sumatriptan administration. Ann Ophthalmol 2001; 33(Suppl 3): 231-232.
14 Winner P, Rothner AD, Saper J, Nett R, Asgharnejad M, Laurenza A et al. A randomized, double-blind, placebocontrolled study of sumatriptan nasal spray in the treatment of acute migraine in adolescents. Pediatrics 2000; 106(5): 989-997.

15 Wilkinson M, Pfaffenrath V, Schoenen J, Diener HC, Steiner TJ. Migraine and cluster headache-their management with sumatriptan: a critical review of the current clinical experience. Cephalalgia 1995; 15(5): 337-357. 